\title{
Human immunodeficiency virus type 1 (HIV-1) genotyping in Rio de Janeiro, Brazil: assessing subtype and drug-resistance associated mutations in HIV-1 infected individuals failing highly active antiretroviral therapy
}

\author{
JC Couto-Fernandez/ ${ }^{+}$, C Silva-de-Jesus, VG Veloso*, M Rachid**, \\ RSG Gracie***, SL Chequer-Fernandez, SM O liveira****, D Arakaki-Sanchez****, \\ PJN Chequer****, MG Morgado
}

\begin{abstract}
Laboratório de AIDS e Imunologia Molecular, Departamento de Imunologia, Instituto Oswaldo Cruz-Fiocruz, Av. Brasil 4365, 21045-900 Rio de Janeiro, RJ, Brasil *Instituto de Pesquisa Clínica Evandro-Chagas-Fiocruz, Rio de Janeiro, RJ, Brasil **Secretaria Estadual de Saúde do Rio de Janeiro, Rio de Janeiro, RJ, Brasil ***Laboratório de Geoprocessamento-DIS/CIC/ Fiocruz, Rio de Janeiro, Brasil *****Programa Nacional de DST e AIDS, Ministério da Saúde, Brasília, DF, Brasil
\end{abstract}

In order to assess the human immunodeficiency virus type 1 (HIV-1) drug resistance mutation profiles and evaluate the distribution of the genetic subtypes in the state of Rio de Janeiro, Brazil, blood samples from $547 \mathrm{HIV}$ 1 infected patients failing antiretroviral (ARV) therapy, were collected during the years 2002 and 2003 to perform the viral resistance genotyping at the Renageno Laboratory from Rio de Janeiro (Oswaldo Cruz Foundation). Viral resistance genotyping was performed using ViroSeq ${ }^{T M}$ Genotyping System (Celera Diagnostic-Abbott, US). The $H I V-1$ subtyping based on polymerase (pol) gene sequences (protease and reverse transcriptase-RT regions) was as follows: subtype B (91.2\%), subtype $F(4.9 \%)$, and B/F viral recombinant forms $(3.3 \%)$. The subtype C was identified in two patients (0.4\%) and the recombinant CRF_O2/AG virus was found infecting one patient $(0.2 \%)$. The HIV-1 genotyping profile associated to the reverse transcriptase inhibitors has shown a high frequency of the M184V mutation followed by the timidine-associated mutations. The K103N mutation was the most prevalent to the nonnucleoside $R T$ inhibitor and the resistance associated to protease inhibitor showed the minor mutations L63P, $L 10 F / R$, and $A 71 V$ as the more prevalent.

A large proportion of subtype B was observed in HIV-1 treated patients from Rio de Janeiro. In addition, we have identified the circulation of drug-resistant HIV-1 subtype $C$ and are presenting the first report of the occurrence of an African recombinant CRF_O2/AG virus in Rio de Janeiro, Brazil. A clear association between HIV-1 subtypes and protease resistance mutations was observed in this study. The maintenance of resistance genotyping programs for HIV-1 failing patients is important to the management of ARV therapies and to attempt and monitor the HIV-1 subtype prevalence in Brazil.

Key words: human immunodeficiency virus type 1 - subtypes - genotyping - resistance - Brazil

The human immunodeficiency virus type 1 (HIV-1) shows remarkable genetic diversity with many implications in pathogenesis, vaccine development, diagnosis, and antiretroviral (ARV) drug susceptibility (Kanki et al. 1999, Caride et al. 2000, Kaleebu et al. 2002).

Antiviral resistance is one of the primary reasons for highly active antiretroviral therapy (HAART) failure over time (Shafer et al. 1998, Vella \& Palmisano 2000). The emergence of HIV-1 drug-resistant variants within treated patients is attributed to viral replication errors due to the fast replication rate. On average, 10 billion HIV particles are produced every day and, associated to the highly error prone nature of the viral reverse transcriptase (RT), at

Financial support: National Program of STD/AIDS, Brazilian Ministry of Health, Faperj, Fiocruz

${ }^{+}$Corresponding author. E-mail: coutofer@ioc.fiocruz.br

Received 7 July 2004

Accepted 8 December 2004 least one new mutation can be introduced in each new virus genome (Mansky 1998). The selection of drug-resistant viruses during the therapy associated to other factors like, adherence, drug pharmacological factors, and host immune response pressure, also contribute to the evolution of HIV-1 drug-resistance in infected patients (reviewed by Simoni et al. 2003).

The knowledge of the HIV-1 resistance patterns has generated information concerning the potential utility of HIV genotyping and phenotyping drug resistance tests for the management of antiretroviral therapy (Hirsch et al. 2000). Genotyping assays for drug resistance determine the nucleotide sequence of HIV-1 protease and RT allowing the detection of resistance associated mutations in the genome that may precede a shift in the phenotyping susceptibility affecting the long-term efficacy of HAART. The primary goal of HIV-1 antiretroviral genotyping is to extend maximal viral suppression for the longest time period, ideally to prevent HIV progression and AIDS complications in treated patients (reviewed by Hisch et al. 2003). 
Since 1996, the Brazilian Ministry of Health has been successfully conducting programs of universal access to antiretroviral therapy, supplying antiretroviral drugs to the majority of HIV-1 infected patients. By December 2003, approximately 130,000 HIV-1 infected patients in this country have been treated by the Public Health System, substantially contributing to the decrease of the mortality and morbidity levels over the last years in Brazil (Marins et al. 2003, Boletim Epidemiológico 2003 - www.aids. gov.br). However, the emergence of viral resistance during HIV-1 infection may compromise the Brazilian policy for HIV-1 infection treatment.

Thus, in order to assess the drug resistance profiles and to improve antiretroviral strategies of therapy in patients failing to respond to previous regimens, the Brazilian Government has established a National Network for HIV Genotyping (Renageno). As a member of this HIV-1 genotyping resistance network composed by 14 laboratories distributed throughout the country, we describe in this paper the HIV-1 drug resistance profile and subtype prevalence in patients failing HAART from state of Rio de Janeiro, Brazil.

\section{MATERIALS AND METHODS}

Population and sample collection - Whole-blood samples from 547 HIV-1 treated-patients that were failing HAART were collected between March 2002 to October 2003 from hospitals distributed through out the state of Rio de Janeiro, Brazil. The genotyping resistance test was performed in patients showing at least tree therapeutic regimen failures, characterized by the persistence of higher viral load counts after continuous use of three or more ARV drugs, including at least one protease inhibitor (IP). All patients were followed at outpatient clinics from the Public Health System and were engaged in the policy of freely accessing ARV drugs sponsored by the Brazilian Ministry of Health. ARV treatment was based on the consensus established by the National Program of STD/AIDS from the Ministry of Health (2003).

Patients fulfilling the ARV failing criteria and approved for performance of the genotyping resistance analysis in the Public Health System, signed a written consent accepting their inclusion in the study. The study was approved by the Brazilian National Committee for Ethics in Research (project-Conep 2857). Plasma samples from each patient were separated, aliquoted and stored at $-80^{\circ} \mathrm{C}$ until processing.

HIV-1 resistance genotyping and subtype determination - The ViroSeq ${ }^{\mathrm{TM}}$ HIV-1 Genotyping System (Celera Diagnostic, Abbott Laboratories, US) was used for the identification of resistance-associated mutations in the HIV-1 polymerase ( $p o l$ ) gene according to the manufacturer. Briefly, the process comprises first the isolation and purification of plasma viral RNAs by ultra centrifugation $(21,000 \mathrm{~g} \times$ for $120 \mathrm{mn}$ - sample preparation module), followed by cDNA synthesis and genomic amplification by polymerase chain reaction assay (PCR) of the HIV-1 pol fragment (RT-PCR and PCR module), spanning the entire protease (PR) gene and approximately two thirds of the RT gene. A 1.8 kilobase $(\mathrm{Kb})$ amplicon fragment was subsequently used as a sequencing template to generate approximately $1.2 \mathrm{~Kb}$ of HIV-1 sequence data.

The amplified PCR products were sequenced using seven primers included in the kit, formulated with the BigDye Terminator sequencing chemistry (Sequencing Module - BigDye v.2.0). The sequencing products were analyzed on an ABI Prism ABI 3100 Genetic Analyzer (Applied Biosystems, US) coupled to the DNA sequencing analysis software.

The ViroSeq ${ }^{\mathrm{TM}}$ HIV-1 Genotyping System consists of a software that automatically imports the sequence data from the sequence analysis software and assembles seven or six sequence segments into a single sequence, which is then compared to the HXB2 reference strain (Kuiken et al. 2002). After the edition and establishment of the consensus sequence, the mutation analysis software (ViroSeq ${ }^{\mathrm{TM}}$ software V.2.6) generates the resistance mutation profiles for the different ARV drugs.

All sequences obtained from samples were subjected to quality control assessments using the Blast-Renageno resistance analysis web (http://aids.gov.br/renageno) to ensure that were no sample mix-ups or contamination. For the determination of the genetic subtype and in order to confirm the HIV-1 resistance profile, all sequences were analyzed using the Stanford Sequence Resistance Database (http://hivdb.stanford.edu).

Mutations were compilated according to the International AIDS Society US consensus (D'Aquila et al. 2002). Samples presenting discordant protease/RT subtyping were further analyzed using the SimPlot program (Ray 1999) to confirm the virus recombinant profile (data not shown).

\section{RESULTS}

A total of 547 HIV-1 infected patients failing ARV therapy from the state of the Rio de Janeiro were sent for genotyping analysis at the Laboratory of AIDS and Molecular Immunology (Renageno Laboratory) of the Oswaldo Cruz Institute-Fiocruz. The majority of the patients $(90 \%)$ resides in the metropolitan region and surrounds (17\% - Niterói and São Gonçalo). The majority of the studied patients (64\%) showed more than 200 cells/ $\mathrm{mm}^{3}$ of CD4 cell counts and plasmatic viral load (80\%) higher than 10,000 copies $/ \mathrm{ml}$. A total of 488 plasma samples (89.2\%) from treated patients were successfully amplified by the PCR technique and consequently genotyped using ViroSeq Genotyping System and the HIV-1 genetic subtypes were also determinated.

A map of the Rio de Janeiro territory showing the distribution of HIV-1 subtypes found across the eight different regions is depicted in Fig.1 (Limonad 1996). From the 488 HIV-1 resistant genotyped patients, we were able to precisely determine the geographical origin for $95.3 \%$ of them. Based on the genotyping database, 445 (91.2\%) samples were classified as subtype B, followed by 24 (4.9\%) subtype F and 16 (3.3\%) viral recombinant forms between subtypes $\mathrm{B}$ and $\mathrm{F}$. The recombinant $\mathrm{B} / \mathrm{F}$ variants showed different recombination patterns when both genomic regions (PR and RT) were analyzed, $11(2.3 \%)$ sequences showed evidence of subtype divergence such as $\mathrm{PR}^{\mathrm{F}} / \mathrm{RT}^{\mathrm{B}}$ and $5(1 \%)$ sequences the profile $\mathrm{PR}^{\mathrm{B}} / \mathrm{RT}^{\mathrm{F}}$. Those divergent genomes together represented $37.2 \%$ of the total of the non-B HIV-1 analyzed samples. 


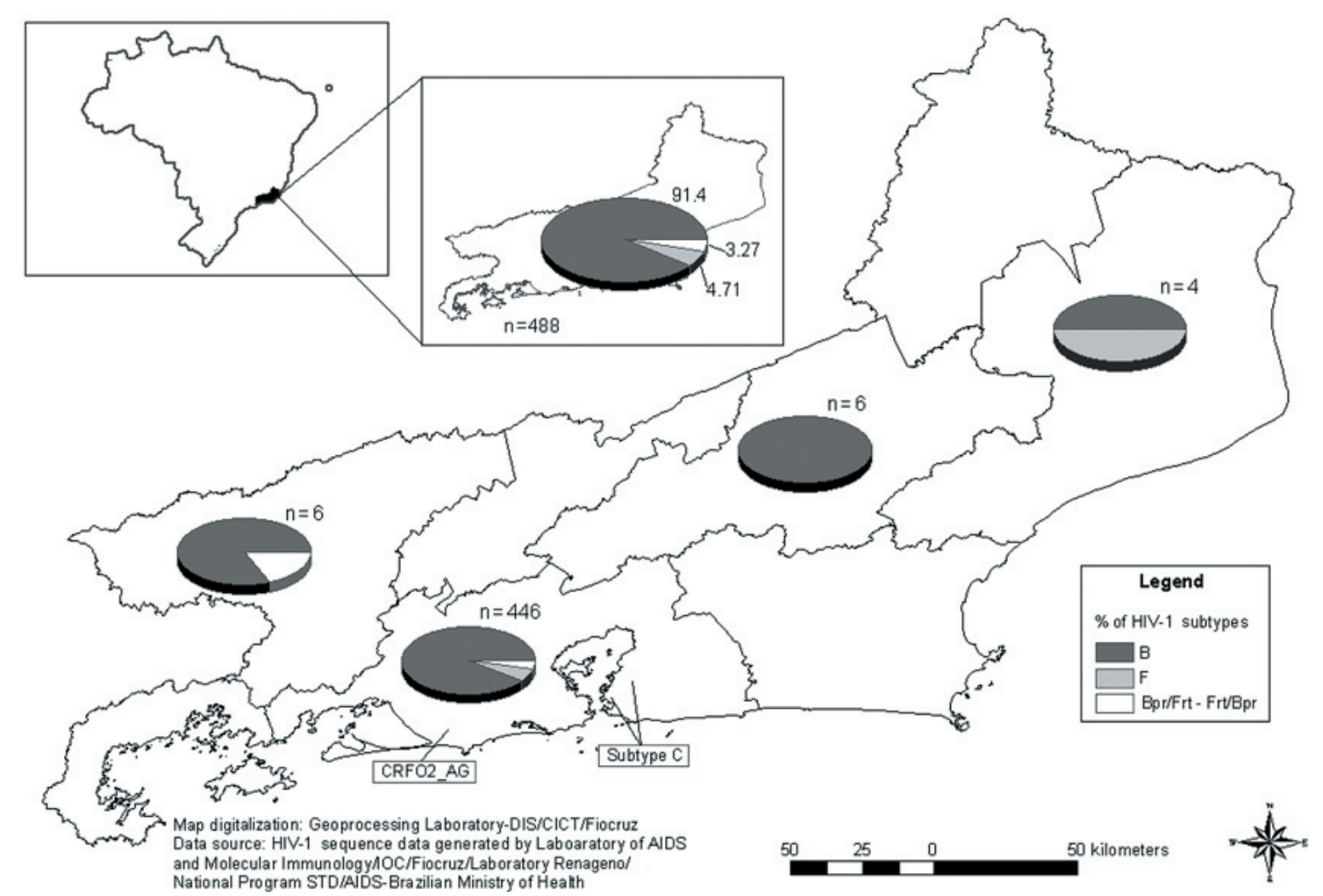

Fig. 1: geographical distribution of the human immunodeficiency virus type 1 genetic subtypes in the state of Rio de Janeiro, Brazil

The subtype $\mathrm{C}$ was identified in two patients $(0.4 \%)$ in the Rio de Janeiro, one from Niterói and the other from São Gonçalo municipal district. The circulating recombinant form CRF-02/AG virus was identified infecting one patient $(0.2 \%)$ in the metropolitan area from Rio de Janeiro. The cumulative prevalence of non-B HIV-1 subtypes was $8.8 \%$ of the total of samples analyzed.

The HIV-1 genotyping resistance profile associated to the ARV drug discriminated according to the subtype $\mathrm{B}$ and non-B infections are shown in Figs 2 and 3. Eight samples $(1.5 \%)$ did not show any mutation associated to ARV resistance. The frequency of ARV mutations in the RT gene (Fig. 2) of HIV-1 positive individuals failing HAART was: M184V (67.7\%), followed by T215Y/F (65.1\%), M41L (53.2\%), D67N (45.2\%), L210W (37.2\%), K70R (30.8\%) and K219Q/E (27.3\%). Overall, 35\% of the individuals included in the present analysis showed an association to four NRTI resistance mutations (M184V, M41L, D67N, T215Y/F).

The K103N NNRTI resistance-associated mutation was the most prevalent $(27.7 \%)$, corresponding to more than $50 \%$ in the non-B viruses, followed by the mutations G190S/A (19.5\%) and Y181C/I (15.8\%), P225H (3.9\%) and $\mathrm{M} 230 \mathrm{~L}$ in four patients $(0.8 \%)$.

The profile of resistance mutations associated to the protease gene (Fig. 3) was the minor mutations, L63P (72.4\%), L10F/R (45.4\%), M36I (36.3\%), A71V (42.1\%), V77I (40.9\%). The most prevalent major mutation found among the ARV failing therapies was L90M (29.6\%), followed by
D30N, I54V and V82A, occurring in $20 \%$ of the patients. There was a clear association of the minor substitutions L63P and M36I with subtype assignment B and non-B, respectively. Moreover, differences on the frequency of drug resistance mutations analysis between $\mathrm{B}$ and non- $\mathrm{B}$ subtype viruses were observed for several positions of the protease and RT genes (Figs 2, 3).

The resistance associated mutations identified in the two cases of HIV-1 subtype C infections were D67N + $\mathrm{K} 70 \mathrm{R}+\mathrm{K} 103 \mathrm{~N}+\mathrm{P} 225 \mathrm{H}$ in the RT gene and K20R + M36I $+\mathrm{V} 82 \mathrm{~A}$ for protease in one patient and, an insertion at 69 position + T69D and K219Q (RT), in association with the substitution M36I (PR) in the other C sample. On the other hand, the CRF_02A/G did not show any resistance associated mutation in RT genes and carried out only the minor mutations L10I and M36I in the protease gene.

\section{DISCUSSION}

Studies performed in developed countries and more recently in Brazil have demonstrated substantial benefits from the ARV treatment in terms of survival and quality of life for patients with AIDS (Detels et al. 2001, Marins et al. 2003). However, the development of drug resistance remains the most serious obstacle to maintain HAART therapy suppressing HIV replication in the infected patient (Vella 2002).

Evidence suggesting the clinical utility of drug resistance testing is being accumulated from retrospective and prospective intervention-based studies (Durant et al. 



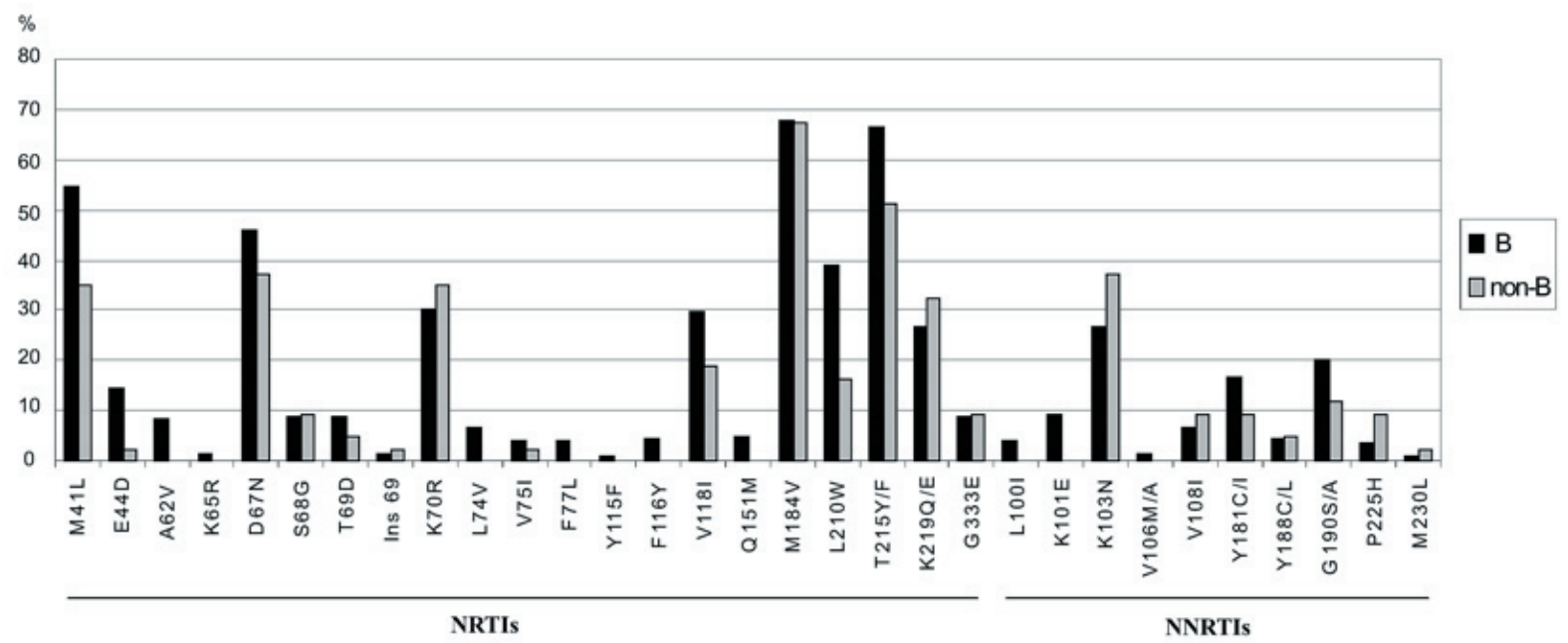

Fisher's exact test: ${ }^{*} \mathrm{p}<0.05$; NRTIs: nucleosid reverse-transcriptase inhibitors

Fig. 2: prevalence of resistance-associated mutations in the reverse transcriptase gene

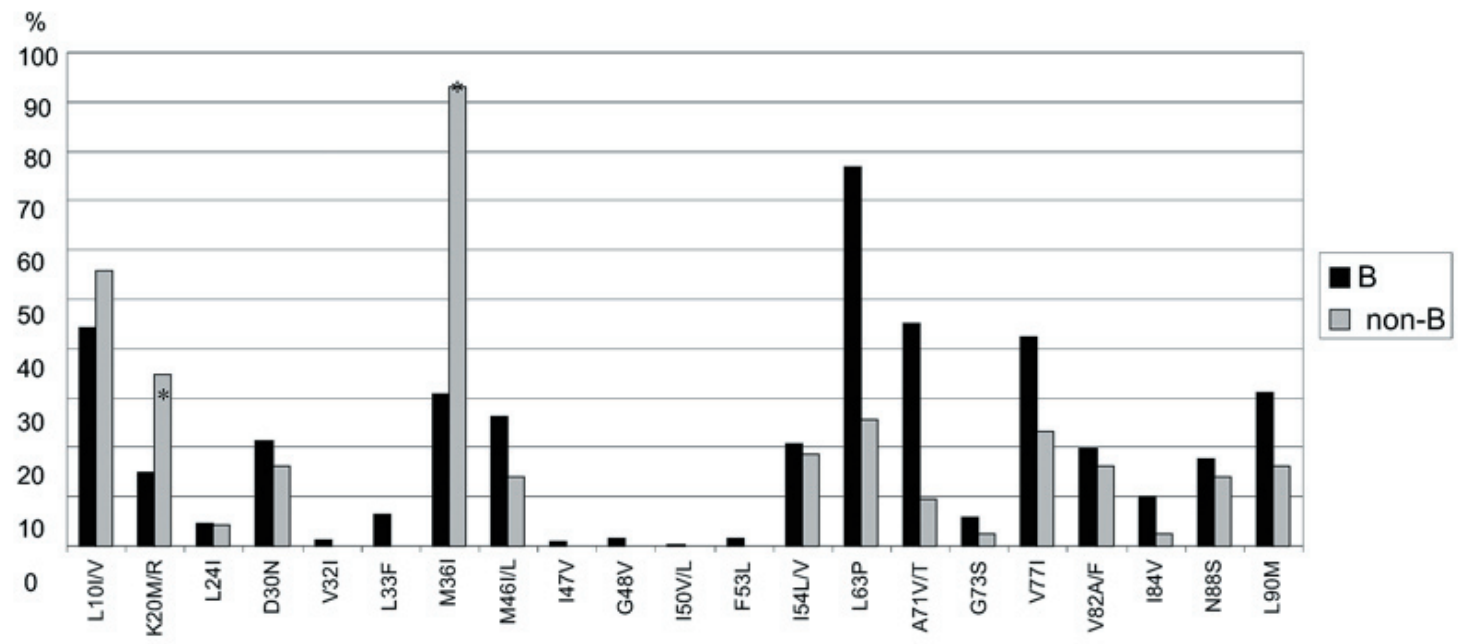

Fisher's exact test: ${ }^{*} \mathrm{p}<0.05$

Fig. 3: prevalence of resistance-associated mutations in the protease gene

1999). In addition, several clinical trials have showed a significant correlation between drug resistance and virologic response to a new treatment regimen when prior therapy has failed (Durant et al. 1999, Baxter et al. 2000, Cohen et al. 2002).

In this molecular epidemiological survey performed in samples obtained from patients failing HAART in all of the Rio de Janeiro State, it was possible to detect a high prevalence of mutations related to drug resistance in RT and/or protease genes, as well as, estimate the prevalence of different genetic subtypes in the state. Our results are in accordance with previous molecular epidemiological studies in Brazil (Tanuri et al. 2002).

A large proportion of HIV-1 subtype B infections was observed in HAART failing patients from Rio de Janeiro, higher than had been previously described for this subtype in the region (Morgado et al. 1998, Bongertz et al. 2000, Brindeiro et al. 2003). Indeed, we have found that almost $92 \%$ of the virus circulating in the state belongs to subtype B. These results would suggest the maintenance of a higher prevalence of HIV-1 subtype B even with the introduction of other non-B subtypes. Moreover, the prevalence of subtype $\mathrm{F}$ was quite low in the present study (4.9\%), even including the B/F recombinant forms $(8.1 \%)$. According to previous results of our laboratory (Morgado et al. 1998) and others (Brindeiro et al. 2003) the prevalence of this subtype in Rio de Janeiro varied around 15\%, based on studies of drug naïve HIV-1 positive individuals within distinct exposure categories. If these differences could be attributed to differential HIV-1 subtype ARV-drug susceptibility has to be further addressed. Only in a very limited number of patients from the west part of the state a similar proportion of B and F subtype infections could be observed (Fig. 1).

We detected two patients infected with subtype $\mathrm{C}$ and presented the first report of the circulation an African 
CRF_02 A/G recombinant form in Brazil. Actually, clade $\mathrm{C}$-related viruses are the most prevalent subtype in the global AIDS epidemic and CRF_02A/G is the recombinant form more prevalent in African countries. In Brazil, we have detected an increased prevalence of subtype $C$ in Brazilian southern-most states (Brindeiro et al. 2003), however, the impact of the new introduction of these African variants in low prevalence regions is totally unknown.

Analyzing the resistance-associated mutations to RT inhibitors in all sequence samples, we observed that the M184V mutation was the most prevalent among B and non-B subtypes. This substitution is associated to an early virologic failure during ARV therapy concomitant with lamivudine (3TC) (Havlir et al. 2000) and its frequency is in agreement to what has been described for HIV patients failing HAART (Wainberg 2004). In addition, 3TC is used largely in Brazil due to its practicality and low toxicity, which might explain the finding of a high proportion of the M184V mutation in the HIV-1 samples studied (67.7\% of the total). The second group of more prevalent RT mutations were the TAMs that lead to strong resistance against the majority of RTI, including Tenofovir. The RT mutation patterns between B and non-B subtypes were basically the same and varied only in the residues related to AZT resistance, which occurred more frequently in subtype B sequences. Among the NNRTI associated mutations, K103N and G190S/A were the most prevalent. Probably this is a consequence of the drug selective pressure in treated patients and also due to the large application of these classes of drugs in the Brazilian therapeutic protocols during the last years, mainly in association with 3TC.

As for the two subtypes $\mathrm{C}$ identified one subject carried the insertion 69 , leading to complete resistance to NTRI, and the other accumulated two TAMs (D67N, K70R) in association with the NNRTI mutations K103N and the $\mathrm{P} 225 \mathrm{H}$. Interestingly, both HIV-1 subtype $\mathrm{C}$ viruses were identified in the Niterói/São Gonçalo municipal districts, near the Rio de Janeiro metropolitan area, showing high demographic concentration. Concerning the recombinant form CRF_02A/G identified in the city of Rio de Janeiro, only minor mutations of the protease were detected. The circulation of non-B resistant subtypes may exercise a great impact in the AIDS epidemic in Rio the Janeiro, the second state in number of AIDS cases in the country (www.aids.gov.br/boletimepidemiologico 2003).

Analyzing the genotyping resistance profile of the protease-associated mutations, many subtype associated differences could be detected only for the minor mutations, such as at residues, 20, 36, 63, 71, and 77 (Fig 3). The minor protease mutations M36I and L63P were associated to non-B and B subtypes, respectively. Such differences could lead to different levels of ARV resistance through different genetic barriers between B and non-B viruses and may influence of progression to resistance during therapy of HIV-1 (Brindeiro et al. 2002). One example of this possible situation was the identification of several minor IP mutations (K20M, M36I) in addition to V82A in the genome of the both HIV-1 subtype $\mathrm{C}$ and in the African recombinant form CRF_02A/G (L10I, M36I).

In summary, association between HIV-1 subtypes and the different resistance mutation profiles associated to IP was clearly observed in the present study. All mutations detected by resistance genotyping analysis were related to the ARV therapy prescribed and $98.5 \%$ of the HIV-1 infected patients failing therapy presented several mutations in the viral genome associated to drug resistance. The selection and circulation of drug-resistant viruses may represent a serious public health problem and may compromise whole the Brazilian AIDS program efforts in controlling the HIV transmission and AIDS mobility/mortality by ARV therapy.

The maintenance of resistance genotyping programs supplied for HIV-1 failing patients is important in the management of HAART therapies and to the attempted monitoring of the HIV-1 subtype prevalence in Brazil.

\section{ACKNOWLEDGMENTS}

To the genotyping reference doctor (MRG) staff from the Rio de Janeiro State Secretariat of Health for the patients recruitment, to Dr Josué Nazareno de Lima from National Program of STD and AIDS for the technical coordination and to Dr Vera Bongertz for reviewing the manuscript.

\section{REFERENCES}

Baxter JD, Mayers DL, Wentworth DN, Neaton JD, Hoover ML, Winters MA, Mannheimer SB, Thompson MA, Abrams DI, Brizz BJ, Ioannidis JP, Merigan TC 2000. A randomized study of antiretroviral management based on plasma genotypic antiretroviral resistance testing in patients failing therapy. CPCRA 046 Study Team for the Terry Beirn Community Programs for Clinical Research on AIDS. AIDS 16: F83-93.

Bongertz V, Bou-Habib DC, Brigido LF, Caseiro M, Chequer, PJN, Couto-Fernandez JC, Ferreira PC, Galvão-Castro B, Greco D, Guimarães ML, Linhares de Carvalho MI. Morgado MG, Oliveira CA, Osmanov S, Ramos CA, Rossini M, Sabino E, Tanuri A, Ueda M 2000. HIV-1 diversity in Brazil: genetic, biologic and immunologic characterization of HIV-1 strains in three potential vaccine evaluation sites. Brazilian Network for HIV Isolation and Characterization. J AIDS Hum Retroviruses 23: 184-93.

Brindeiro R, Diaz, R, Sabino E, Morgado M, Pires I, L Brígido L, Dantas M, Barreira D, Teixeira P, Tanuri A and the Brazilian Network for Drug Resistance Surveillance 2003. Brazilian Network for HIV Drug Resistance Surveillance (HIVBResNet): a survey of chronically infected individuals. AIDS 17: 1063-1069.

Boletim Epidemiológico 2003. Programa Nacional de DST e AIDS, Ministério da Saúde - MS-PNDST/AIDS, Ano XVII no. 01, 01 a 52 semanas epidemiológicas janeiro a dezembro (www.aids.gov.br/boletimepidemiologico).

Caride E, Brindeiro R, Hertogs K, Lader B, Dehertogh P, Machado E, Moraes-de-Sá CA, Eyer-Silva WA, Sion FS, Passioni LF, Menezes JA, Calazans AR, Tanuri A 2000. Drug-resistance reverse transcriptase genotyping and phenotyping of B and non-B subtypes ( $F$ and $A$ ) of human immunodeficiency virus type 1 found in brazilian patients failing HAART. Virology 15: 107-115.

Cohen NJ, Oram R, Elsen C, Englund JA 2002. Response to changes in antiretroviral therapy after genotyping in human immunodeficiency virus-infected children. J Pediatr Infect Dis 21: 647-53. 
D'Aquila RT, Schapiro JM, Brun-Vézinet F, Clotet B, Conway B, Demeter LM, Grant RM, Johnson VA, Kuritzkes DR, Loveday C, Shafer RW, Richman DD, International AIDS Society-USA 2002. Drug resistance mutations in HIV-1. Top HIV Med 10: 21-25.

Detels R, Tarwater P, Phair JP, Margolick J, Riddler SA, Munoz A, Multicenter AIDS Cohort Study 2001. Effectiveness of potent antiretroviral therapies on the incidence of opportunistic infections before and after AIDS diagnosis. AIDS 15: 347-55.

Durant J, Clevenbergh P, Halfon P, Delgiudice P, Porsin S, Simonet P, Montagne N, Boucher CA, Schapiro JM, Dellamonica P 1999. Drug-resistance genotyping in HIV-1 therapy: the Viradapt randomised controlled trial. Lancet 353: 2195-2199.

Havlir DV, Hellmann NS, Petropoulos CJ, Whitcomb JM, Collier AC, Hirsch MS, Tebas P, Sommadossi JP, Richman DD 2000. Drug susceptibility in HIV infection after viral rebound in patients receiving indinavir-containing regimens. JAMA 283: 229-234.

Hirsch MS, Richman DD 2000. The role of genotypic resistance testing in selecting therapy for HIV. JAMA 284: 16491650 .

Hirsch MS, Brun-Vézinet F, Clotet B, Conway B, Kuritzkes DR, D’Áquila RT, Demeter LM, Hammer SM, Johnson VA, Loveday C, Mellors JW, Jacobsen DM, Richman DD 2003. Antiretroviral drug resistance testing in adults infected with human immunodeficiency virus type 12003 . Recommendations of an International AIDS Society-USA panel. Clin Infect Dis 37: 113-128.

Kaleebu P, French N, Mahe C, Yirrell D, Watera C, Lyagoba F, Nakiyingi J, Rutebemberwa A, Morgan D, Weber J, Gilks C, Whitworth J 2002. Effect of human immunodeficiency virus (HIV) type 1 envelope subtypes A and D on disease progression in a large cohort of HIV-1-positive persons in Uganda. J Infect Dis 185: 1244-1250.

Kanki PJ, Hamel DJ, Sankale JL, Hsieh CC, Thior I, Barin F, Woodcok AS, Gueye-Ndiaye A, Zhang E, Montano M, Siby T, Marlink R, Ndoye I, Essex ME, Mboup S 1999. Human immunodeficiency virus type 1 subtypes differ in disease progression. J Infect Dis 179: 68-73.

Kuiken C, Foley B, Freed E, Hahn B, Marx P, McCutchan F, Mellors J, Wolinsky S, Korber B 2002. HIV Sequence Compendium, Los Alamos National Laboratory, US.

Limonad E 1996. Os Lugares da Urbanização - O Caso do
Interior Fluminense, PhD Thesis, USP, São Paulo.

Marins JR, Jamal LF, Chen SY, Barros MB, Hudes ES, Barbosa AA, Chequer P, Teixeira PR, Hearst N 2003. Dramatic improvement in survival among adult Brazilian AIDS patients. AIDS 17: 1675-1682.

Mansky LM 1998. Retrovirus mutation rates and their role in genetic variation. J Gen Virol 79: 1337-1345.

Morgado MG, Guimarães ML, Neves Jr I, Veloso dos Santos VG, Linhares-de-Carvalho MI, Bastos FI, Castilho EA, Galvão-Castro B, Bongertz V, HEC AIDS Clin Res Group 1998. Molecular epidemiology of HIV in Brazil: polymorphism of the antigenically distinct subtype B isolates. Mem Inst Oswaldo Cruz 93: 383-386.

Osmanov S, Pattou C, Walker N, Schwardlander B, Esparza J, WHO-UNAIDS Network for HIV Isolation and Characterization 2002. Estimated global distribuition and regional spread of HIV-1 genetic subtypes in 2000. J Aquir Immune Defic Synd 29: 184-190.

Ray SC 1999. Simplot for Windows version 2.5 (Distributed by the author, http//w.w.w.med.jhu.edu/depmed/sry/down$\operatorname{load} /)$.

Simoni JM, Frick PA, Pantalone DW, Turner BJ 2003. Antiretroviral adherence interpretations: A review of current literature of ongoing studies. Topics in HIV Medicine, IAS-Drug resistance mutations group 11: 185-199.

Shafer RW, Winters MA, Palmer S, Merigan TC 1998. Multiple concurrent reverse transcriptase and protease mutations multidrug resistance of HIV-1 isolates from heavily treated patients. Ann Intern Med 128: 906-911.

Tanuri A, Caride E, Dantas MC, Morgado MG, Mello DL, Borges S, Tavares M, Ferreira SB, Santoro-Lopes G, Martins CR, Esteves AL, Diaz RS, Andreo SM, Ferreira LA, Rodrigues R, Reuter T, Cavalcanti AM, de Oliveira SM, de Barbosa HB, Teixeira PR, Chequer PN 2002. Prevalence of mutations related to HIV-1 antiretroviral resistance in Brazilian patients failing HAART. J Clin Virol 25: 39-46.

Vella S 2002. Antiretroviral drug resistance and HIV/AIDS in the developing world. J HIV Ther 7: 53-55.

Vella S, Palmisano L 2000. Antiviral therapy: state of the HAART. Antiviral Res 45: 1-7.

Wainberg MA 2004. The impact of the M184V substitution on drug resistance and viral fitness. Expert Rev Anti Infect Ther 2: 147-51. 